\title{
Optimizing Diabetes Control in Geriatric Patients
}

\author{
Emad I. Hammouda ${ }^{1 *}$, Sarah E. Hammouda ${ }^{1}$ \\ Correspondence: emhammouda@hotmail.com \\ ${ }^{1}$ Faculty of Pharmacy, Al Ain University, UAE.
}

\begin{abstract}
Diabetes mellitus is approaching epidemic proportions in most countries and has captured the attention of physicians on local, national and global levels. The elderly population remains at a higher risk for diabetes mellitus [1], and the disease poses unique concerns for geriatricians, primary care physicians, nurses, dietitians and specialized pharmacists who provide care to the elderly. Glycemic control, geriatric related syndromes, and cardiovascular risk factors considerably affect the elderly patient's functional status and life expectancy [2]. Geriatric syndromes include polypharmacy, chronic pain, injurious falls, cognitive impairment, urinary incontinence, and depression. Higher rates of premature death; functional disability; and chronic illnesses, such as hypertension, cerebrovascular accidents, dementia and coronary artery disease, often affect elderly diabetic patients. Collaborative efforts are continually needed to allocate and maximize utilization of resources to help empower older adults with diabetes to overcome barriers to disease management. Healthcare providers are increasingly challenged by the complexity of problems that face old patients, and must therefore be prepared to assess and treat diabetes mellitus within the milieu of many geriatric related chronic illnesses. Healthcare providers must tailor individualized treatment methods, with the ultimate goal of not only achieving laboratory norms but also improving the quality of life for this vulnerable population. This article emphasizes the necessity of needed extra care to optimize diabetes control in old patients as a dynamic and a continuous task that needs coordination of healthcare systems and professionals at all levels of care.
\end{abstract}

keywords: Diabetes contol, geriatrics

\section{Background}

The global prevalence of diabetes is rising, attributable to an increase in new cases driven by higher obesity rates and the aging population, and declining of mortality [3]. Aging is associated with declining beta cell function, lower blood insulin levels, and increased insulin resistance [4]. Most developed world countries have accepted the chronological age of 65 years as a definition of 'elderly' or older person. It is expected to nearly double over the next 25 years and rates of diabetes are expected to continue rising. The older adult population is heterogeneous with wide variations in functional status, comorbidities, and life expectancy. In this article, the focus is to highlight the barriers to diabetes control in geriatrics and how to sustainably overcome them. Cardiovascular risk in old patients with diabetes is one of the main concerns in dealing with their overall management. Treatment strategies should take into consideration individual patient factors, as well as quality of life and patient preference.

\section{Limits to diabetes care in elderly}

Limits to control diabetes in elderly can be either personal or healthcare system related.
Patient related limits may include:

1. Educational of low knowledge of the disease or the service.

2. Finance issue.

3. Adherence.

4. Comorbidities.

5. Group pressure.

6. Prejudice (e.g., racism or against those with diabetes).

7. Lack of family support.

8. Communication difficulties (literacy, audiovisual impairment).

9. Difficulty setting priorities.

10. Poor self motivation.

11. Emotional issues.

Healthcare related limits may include:

1. Communication difficulties.

2. Limited range of services.

3. Understaffing.

4. Staff motivation.

Ways to help overcome limits in old patients A. Patient related limits:

1. Education: Diabetes self-management education has been shown to improve preventive care practices and

(c) 2012 Hammouda et al; licensee Herbert Publications Ltd. This is an open access article distributed under the terms of Creative Commons Attribution License (http://creativecommons.org/licenses/by/3.0), This permits unrestricted use, distribution, and reproduction in any medium, provided the original work is properly cited 
clinical outcomes. A systematic review of published studies addressing the effectiveness of population-based diabetesrelated interventions recommends diabetes self-management education [5]. Diabetes self-management education empowers people to better manage diabetes through education about nutrition, medication and insulin therapy, stress management, exercise and preventive foot and eye care [6]. Providing counseling, guidance, and support should be a higher priority, along with the traditional clinical and educational responsibilities.

2. Effective communication through listening and opening a free channel of flow of ideas between patients and providers.

3. Medication Management: Older individuals with diabetes may be at greater risk of experiencing treatmentrelated complications than younger persons. For example, metformin treatment, particularly when administered in combination with sulfonylureas, has been associated with higher mortality [7]. Current antipsychotic treatment with atypical antipsychotics was associated with a higher risk for hyperglycemia in elderly compared with remote antipsychotic use in all diabetes-treatment group users who had discontinued their antipsychotics for at least 180 days [8]. Polypharmacy can be regulated and monitored through close collaboration between pharmacy staff and the treating physician. Medication reconciliation should be performed during each patient visit or post discharge. Simplification of regimen may help patients to adhere for given recommendations.

4. Problem solving: doctors, nurses, or any other member of the diabetes care team could play the role of patient related problems solver. The existing diabetes care team takes on the responsibility of helping patients go through services provided and systematically identifies barriers and ensuring that relevant resources (human, welfare, educational) are made available to patients.

5. Case Management: cost, frustrations, group pressure, accessibility to service and Poor self motivation are examples of patient related barriers that can be handled effectively by a competent case manager in order to optimize treatment. Enhancement of family and social support will help solving old patient related problems. Looking for funds to sustain existing programs and to establish new programs is a way to promote serving low income old patients. Treatment and prevention of complications in old patients is cost effective although health economic models have suggested that the benefits of treating glycemia may be somewhat less in older than in younger patients [9].

\section{B. Healthcare related limits:}

1. Leadership: commitment of leadership is the cornerstone to improve quality of service and motivate staff.
2. Motivation: payment for performance and reimbursement for services provided by pharmacy counseling may motivate and encourage healthcare professionals to excel in their provision of care to diabetic patients.

3. Staffing: Recruitment of new staff may help overcome delays in appointments provided that will support the revenue cycle.

4. Communication: Training and continued staff development is a crucial factor along with medical education to update staff with needed information necessary to upgrade service level.

\section{Prevention of Diabetes Complications in geriatric population: \\ Ways of preventing diabetes complications may include:}

1. Promoting smoking cessation since it

has been suggested that it will decrease

the risk of leg ischemia [10].

2. Instructing patients to inspect their feet in a daily basis, eyes every year and teeth every two years and to refer to the treating clinician for any unusual symptoms or continued discomfort.

3. Monitoring blood glucose, A1c and urine protein as recommended. Frail elderly persons are at higher risk for severe hypoglycemia than healthier seniors and need to be monitored aggressively [11]. Tight glycemic control (Figure 1)is a prerequisite in old patients because it has been found that hyperglycemia, hyperinsulinemia, and insulin resistance could be risk factors for the formation of neuritic plaques (NPs), a type of Alzheimer's disease pathologic outcome [12].

4. Lowering Blood Pressure to less than 130/80. Currently, the recommended blood pressure for individuals with diabetes is less than or equal to130/80 $\mathrm{mmHg}$ [13].

5. Treating dyslipidemia: The vast majority of older adults with diabetes will be considered high risk for vascular events. Therefore, in accordance with the Canadian Diabetes Association Guidelines and the Canadian Dyslipidemia Guidelines, first-line therapy should be with a statin to achieve a target LDL-C of less than or equal to $2.0 \mathrm{mmol} / \mathrm{L}$ whenever possible [13].

6. Weight reduction if needed.

7. Adequate dietary fiber intake since a low intake of dietary fiber in men over the age of 60 years is associated with an increased risk of type 2 diabetes [14].

8. Exercise most days of the week for 30 minutes or more.

\section{Special Needs of Elderly with Diabetes:}

1. Emphasis on team work throughout the continuum of patient care. As interdisciplinary interventions have been shown to improve glycemic control in older adults with diabetes, these individuals should be referred to a diabetes health care team [13]. Older adults with recent onset of diabetes do not present with the classic 3 Ps: 


\footnotetext{
The choice of a target level for glycemic control in an older adult must be individualized.

The greatest benefit in improvement in microvascular complications is achieved when $\mathrm{HbA1c}$ is decreased from a high level to about $7.0 \%$.

An individual's life expectancy is a key consideration in determining a target A1c level.

A tighter glycemic target of $\mathrm{HbA1c}<7.0 \%$ may not be appropriate for older adults who are at risk for or have a history of severe hypoglycemia or for older adults with previous macrovascular disease, advanced microvascular disease, a longer duration of diabetes, or multiple comorbid conditions.

A select subgroup of older diabetics with no previous cardiovascular disease, a shorter duration of diabetes, and a relatively lower $\mathrm{HbA1c}$ (around 8.0\%) may benefit from tighter glycemic control of $\mathrm{HbA1c}(<7.0 \%)$.

Management of blood pressure and cholesterol and smoking cessation are critical aspects of diabetes care.

The treatment of diabetes has to be planned as part of holistic care for older individuals, in whom the treatment of multiple medical conditions must be prioritized and individualized.
}

Figure 1: Recommendations for older adults with diabetes.

polyphagia, polydipsia, and polyuria. These patients may only present with falls, urinary incontinence, fatigue, lethargy, weight loss, and decreased cognition.

2. Individualized education through effective listening, suitable product selection to consider manual dexterity, vision, hearing, and memory changes. Providing information does not guarantee behavior change. Simplifying regimen is a wise option to promote adherence.

3. Screening for depression since the prevalence is higher in this population. Ask the patient the following questions:

1. "Do you often feel sad or depressed?"

2. "During the past month, have you been bothered by feeling down, depressed, or hopeless?"

3. "During the past month, have you been bothered by little interest or pleasure in doing things?"

If the answer is yes then the patient may be kept under close observation or referred to a psychiatrist for further evaluation especially if a considerable amount of medications are kept unused at the next visit or lab values are out of range. Several screening tools are available to the clinician for detecting depression in the elderly. One such tool, the geriatric depression scale (GDS) [15], is a standardized measure that is used in common practice. Treatment should be directed at stopping medications known to cause depression and introducing, if necessary, effective medications with good safety profiles in the elderly.

4. Enhancement of social and family support through building rapport with relatives and care givers at home.

5. Adaptation for cognitive changes though -Limit information, frequent repetition and short sentences.
-Combine verbal and written instructions -Concrete examples and obtaining feedback -Allowing needed time for full understanding

6. Reducing fall risks since they are increased in elderly with diabetes due to diabetes complications such as

a. Peripheral Neuropathy (sensory and motor...pain)

b. Altered foot structure (Charcot foot)

c. Muscle Weakness (decreased strength)

d. Orthostatic Hypotension

e. Decreased Vision

f. Risk of hypo and hyperglycemia (nocturnal polyuria, incontinence)

g. Polypharmacy

7. Osteoporosis management as diabetes increases risk of osteoporosis leading to increased risk for falls and fractures. Decreased insulin leads to calcium loss through urine, and decreased absorption from food. Risk may be decreased by increasing exercise, smoking cessation, and avoiding alcohol.

8. Nutrition care for better diabetes control. In elderly aging changes that affect diabetes nutrition may include:

-Taste and smell changes

-Dentition changes, Chewing and Swallowing difficulties

-Changing food preferences

-Changing metabolic rate and decreasing activity

-Cooking capabilities

-Appetite and interest in food changes

-Medications effects on appetite or sleep pattern

-Financial constraints

-Emotional well-being and memory impairment

-Fluid intake 


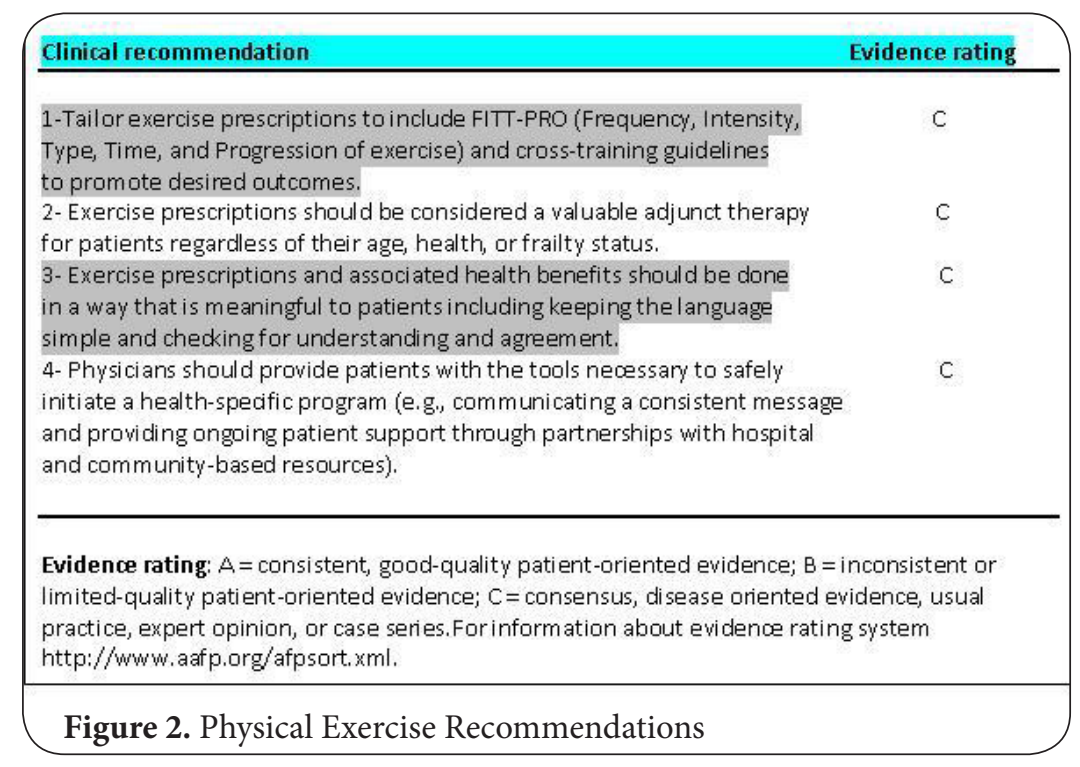

\footnotetext{
-Alcohol use

. Overcoming nutrition difficulties in older adults may be managed through:

. Strengthening willpower for behavior changes

. Introduction of small changes and building on them weekly

. Communicating changes made with healthcare providers and encourage reinforcing those behaviors.

. Timing of meals and allowing for

flexibility in social occasions.

. Use of smaller salad plates.

.Encouraging family to eat same foods.

9. Cognitive changes, dementia and memory problems may be handled through relatives support, avoiding look a like medications and close observation. Because increased cognitive difficulties are frequently seen in the geriatric patient with diabetes, screening in the initial stages of treatment is invaluable as disease progresses. In adult diabetics with cognitive impairment, higher levels of social support for diabetes care may ameliorate the poor glycemic control often seen in these patients [16]. The presence of diabetes mellitus in people with mild cognitive impairment is associated with an increased risk for progression to dementia [17].

10. Addressing polypharmacy and overuse because every time another medication is added, there is a chance of the drugs being taken correctly. Education is a key to addressing polypharmacy, and the current American Geriatrics Society (AGS) guidelines encourage physicians to educate patients and their caregivers regarding the indications, expected risks, and expected benefits of the many medications used to treat elderly patients with diabetes [18].
}

11. Medication management through proper selection of containers, forms, avoiding interactions and medication reconciliation in each visit.

12. Promoting physical activity that is individually matched and considering comorbidities (Figure 2). Use of a pedometer is encouraged to increases daily steps and help for actual measurement of daily activity. Daily exercise may improves insomnia, increase insulin sensitivity [19], decreases need for medication for glycemic control, helps reverse mild depression [20], and increases muscle mass, strength and endurance. Physical activity also reduces arthritis pain, improves longevity, diminishes fall risk, improves functional status and improves quality of life [21]. The most common injuries for older women are musculoskeletal (e.g., falls and joint injuries) and do not usually require medical attention. These minor injuries can be avoided with inclusion of a 5-10 minute warm-up and similar cool-down in the exercise prescription [22].

\section{Conclusion}

Diabetes care is complex; however, many of the limitations to both quality of life and clinical outcomes can now be identified and overcome from the patient, caregiver, and practitioner perspectives. Optimizing diabetes control in older adults requires:

1. Continually updating healthcare professionals' knowledge about diabetes control guidelines, and available resources.

2. Tailoring treatment to individual patients.

3. Empowering patients with the knowledge, skills, adaptations, and confidence they desire and need to live well with their diabetes and make informed daily decisions about their disease control. 


\section{Competing interests}

The authors declare that they have no competing interests.

Publication history

Editor: N Bagchi, Wayne State University, USA.

Received: 30-Mar-2012 Revised: 28-Apr-2012

Re-Revised: 02-June-2012 Accepted: 21-June-2012

Published: 30-July-2012

\section{References}

1. Harris MI, Flegal KM, Cowie CC, Eberhardt MS, Goldstein DE, Little RR, et al.: Prevalence of diabetes, impaired fasting glucose, and impaired glucose tolerance in U.S. adults. The Third National Health and Nutrition Examination Survey, 1988-1994. Diabetes Care 1998; 21;(4.);518-24. | Article | PubMed

2. Brown AF, Mangione CM, Saliba D, Sarkisian C. Plenary Symposium: Release of the California Healthcare Foundation/ American Geriatrics Society Guidelines for Improving the Care of the Older Person with Diabetes Mellitus. Program and abstracts of the American Geriatrics Society 2003 Annual Scientific Meeting; May 13-18, 2003; Baltimore, Maryland. ACPE\# 203-999-03-658-L01.

3. Lipscombe LL, Hux JE: Trends in diabetes prevalence, incidence, and mortality in Ontario, Canada 1995-2005: a population-based study. Lancet 2007; 369;(9563.);750-6.| Article | PubMed

4. Hornick T, Aron DC: Managing diabetes in the elderly: go easy, individualize. Cleve Clin J Med 2008; 75;(1.);70-8. | Article | PubMed

5. Recommendations for healthcare system and self-management education interventions to reduce morbidity and mortality from diabetes. Am J Prev Med 2002; 22;(4 Suppl.);10-4. | Article | PubMed

6. Mensing C, Boucher J, Cypress M, Weinger K, Mulcahy K, Barta $P$, et al:: National standards for diabetes self-management education. Task Force to Review and Revise the National Standards for Diabetes Self-Management Education Programs. Diabetes Care 2000; 23;(5.);682-9. | Article | PubMed

7. Fisman EZ, Tenenbaum A, Benderly M, Goldbourt U, Behar S, Motro M: Antihyperglycemic treatment in diabetics with coronary disease: increased metformin-associated mortality over a 5-year follow-up. Cardiology 1999; 91;(3.);195-202. | PubMed

8. Lipscombe LL, Levesque L, Gruneir A, Fischer HD, Juurlink DN, Gill SS, et al:: Antipsychotic drugs and hyperglycemia in older patients with diabetes. Arch Intern Med 2009; 169;(14.);1282-9. | Article | PubMed

9. De Lissovoy G, Ganoczy DA, Ray NF: Relationship of hemoglobin A1c, age of diabetes diagnosis, and ethnicity to clinical outcomes and medical costs in a computer-simulated cohort of persons with type $\mathbf{2}$ diabetes. Am J Manag Care 2000; 6;(5.);573-84. | Article | PubMed

10. Quick CR, Cotton LT: The measured effect of stopping smoking on intermittent claudication. Br J Surg 1982; 69 Suppl;(S24-6. | Article | PubMed

11. Shorr RI, Ray WA, Daugherty JR, Griffin MR: Incidence and risk factors for serious hypoglycemia in older persons using insulin or sulfonylureas. Arch Intern Med 1997; 157;(15.);1681-6. | Article | PubMed

12. Matsuzaki T, Sasaki K, Tanizaki Y, Hata J, Fujimi K, Matsui Y, et al.: Insulin resistance is associated with the pathology of Alzheimer disease: the Hisayama study. Neurology 2010; 75;(9.);764-70. | Article | PubMed

13. Canadian Diabetes Association 2008 Clinical Practice Guidelines. Canadian Journal of Diabetes. September 2008;32(Suppl 1): S29, S37, S107, S115, S181.

14. Wannamethee SG, Whincup PH, Thomas MC, Sattar N: Associations between dietary fiber and inflammation, hepatic function, and risk of type $\mathbf{2}$ diabetes in older men: potential mechanisms for the benefits of fiber on diabetes risk. Diabetes Care 2009; 32;(10.);1823-5. | Article | PubMed Abstract | PubMed Full Text

15. Yesavage JA. Geriatric depression scale. Psychopharmacol Bull. 1988;24:709-711.

16. Okura T, Heisler M, Langa KM: Association between cognitive function and social support with glycemic control in adults with diabetes mellitus. J Am Geriatr Soc 2009; 57;(10.);1816-24. | Article | PubMed Abstract | PubMed Full $\underline{\text { Text }}$

17. De Lissovoy G, Ganoczy DA, Ray NF: Relationship of hemoglobin A1c, age of diabetes diagnosis, and ethnicity to clinical outcomes and medical costs in a computer-simulated cohort of persons with type 2 diabetes. Am J Manag Care 2000; 6;(5.);573-84. | Article | PubMed

18. Brown AF, Mangione CM, Saliba D, Sarkisian CA: Guidelines for improving the care of the older person with diabetes mellitus. J Am Geriatr Soc 2003; 51;(5 Suppl Guidelines.);S265-80. | Article | PubMed

19. Sigal RJ, Kenny GP, Wasserman DH, Castaneda-Sceppa C, White RD: Physical activity/exercise and type 2 diabetes: a consensus statement from the American Diabetes Association. Diabetes Care 2006; 29;(6.);1433-8. | Article | PubMed

20. Heath JM, Stuart MR: Prescribing exercise for frail elders. $J$ Am Board Fam Pract 2002; 15;(3.);218-28. | Article | PubMed

21. Oldridge NB: Outcome assessment in cardiac rehabilitation. Health-related quality of life and economic evaluation. J Cardiopulm Rehabil 1997; 17;(3.);179-94. | Article | PubMed

22. American College of Sports Medicine Position Stand. The recommended quantity and quality of exercise for developing and maintaining cardiorespiratory and muscular fitness, and flexibility in healthy adults. Med Sci Sports Exerc 1998; 30;(6.);975-91. | Article | PubMed 